\title{
O ENSINO DA FILOSOFIA NO BRASIL: UM MAPA DAS CONDIÇÕES ATUAIS*
}

\author{
Altair Alberto Fávero** \\ Filipe Ceppas \\ Pedro Ergnaldo Gontijo \\ Sílvio Gallo \\ WaLter OMAR KOHAN
}

\begin{abstract}
RESUMO: O presente texto é resultado de uma pesquisa desenvolvida no Brasil em 2003, por solicitação da UNESCO, visando a mapear as condiçôes do ensino de filosofia no país em seus diversos níveis, com especial ênfase na educação média. Não se constitui, portanto, num esforço analítico, mas oferece uma descrição, a mais detalhada possível, das distintas condições do ensino de filosofia nas diversas regiōes brasileiras naquele momento.
\end{abstract}
Palavras-chave: Filosofia. Ensino de filosofia. Parâmetros Curriculares Nacionais. Ensino médio.

* Este texto foi produzido a partir das respostas a um questionário da UNESCO sobre ensino de filosofia. Os autores responderam regionalmente, sob coordenação-geral de Walter Kohan. Os autores agradecem a colaboração das seguintes pessoas que forneceram dados valiosos para o relatório: Conceição Gislane Nóbrega Lima de Salles (doutoranda em Educação, Universidade Federal de Pernambuco, Recife); Eliza Bartolozzi (subsecretária de Educação do Espírito Santo); Elsa Marisa Muguruza Dal Lago (mestranda em Física da Universidade Federal da Bahia e Professora da Faculdade Batista Brasileira, Salvador, BA); Geraldo Bauduíno Horn (professor da Universidade Federal de Paraná); Helder Buenos Aires de Carvalho (professor da Universidade Federal do Piauí); Josué Cândido da Silva (professor da Universidade Estadual de Santa Cruz, Ilhéus, BA); Najla Velloso Sampaio Barbosa (ex-coordenadora de Ensino Fundamental do Ministério de Educação); e Walter Matias Lima (professor da Universidade Federal de Alagoas).

** As instituições e e-mails dos respectivos autores são: Universidade de Passo Fundo (UPF) (favero@upf.tche.br); Universidade do Estado do Rio de Janeiro (EURJ) (filcepps@terra.com.br); Secretaria de Estado de Educação do Distrito Federal (SEE-DF) (pedroegontijo@uol.com.br); Universidade Estadual de Campinas (UNICAMP) (gallo@unicamp.br); Universidade do Estado do Rio de Janeiro (EURJ) (walterk@uerj.br) 
THE TEACHING OF PHILOSOPHY IN BRAZIL:

A MAP OF THE CONTEMPORARY SITUATION

ABSTRACT: This article results from a research developed in Brazil in the year 2003, in accordance with the request of UNESCO, aiming at outlining the conditions of philosophy teaching in this country, in their variegated levels, with special emphasis in high school. Therefore, the article does not constitute an analytical effort but offers a description in the most detailed way of the diverse conditions of the teaching of philosophy in different Brazilian regions in this moment

Key words: Philosophy. Teaching philosophy. National Curricular Parameters. High school.

$\mathcal{E}$ ste texto foi escrito a partir de uma coleta de dados norteada por um questionário da UNESCSO, destinado a mapear o ensino de filosofia em cada país, em especial, na educação média, além de avaliar o impacto que o programa "Olimpíadas de Filosofia", patrocinado por aquele órgão, exerce sobre esse ensino. Embora no Brasil ainda não realizemos as "Olimpíadas", o levantamento destes dados, apesar de trabalhoso e em muitos momentos dificultado por problemas estruturais e de registro, deu-nos condições de, pela primeira vez nas últimas décadas, produzir um mapa, o mais completo possível, sobre o ensino da filosofia no ensino médio no Brasil.

Isso é o que nos anima a trazê-lo a público, na forma de artigo. Que o leitor não espere encontrar aqui análises aprofundadas sobre a questão; longe disso, nossa intenção é a de apresentar os dados coletados - certamente parciais e incompletos - da forma mais clara possível, fazendo apenas alguns ensaios crítico-analíticos.

$\mathrm{O}$ texto que segue está organizado em três partes. A primeira trata das disciplinas de filosofia nos espaços curriculares do ensino médio analisando, para tanto, o contexto legal e as mudanças introduzidas pela Lei n. 9.394/96, bem como a trajetória da discussão em torno do projeto de lei complementar que previa a substituição do artigo 36 da LDB; em seguida apresenta um mapa detalhado do funcionamento dos cursos de filosofia em cada região do Brasil; a filosofia nos demais níveis de ensino (fundamental e superior); e, por fim, um balanço da atual configuração do ensino de filosofia no ensino médio. A segunda parte trata dos programas, mé- 
todos e materiais de apoio utilizados no ensino de filosofia no ensino médio. A terceira parte passa em revista a formação dos professores de filosofia e o exercício profissional.

Depois das referências bibliográficas, como Apêndice ao artigo, apresentamos uma lista das diversas associações regionais que estão voltadas para o apoio ao ensino da filosofia, nos mais diversos aspectos.

\section{As disciplinas de filosofia nos espaços curriculares do ensino médio}

\section{Contexto legal e mudanças recentes}

Como sabemos, o artigo 36 da Lei de Diretrizes e Bases da Educação Nacional (Lei n. 9.394/96), ${ }^{1}$ determina que, ao final do ensino médio, todo estudante deverá "dominar os conhecimentos de filosofia e de sociologia necessários ao exercício da cidadania”. Este foi um avanço significativo para a presença da filosofia nesse nível de ensino, uma vez que em 1961 (com a Lei n. 4.024/61), a filosofia deixa de ser obrigatória e, a partir de 1971 (com a Lei n. 5.692/71), época do regime militar, ela praticamente desaparece das escolas.

Com as Diretrizes Curriculares Nacionais para o Ensino Médio (Resolução CEB/CNE n. 3/98), aprovadas pelo Conselho Nacional de Educação em 1998, e os PCNEM (de 1999), os responsáveis oficiais pela política educacional do período - ministro, membros da Secretaria de Educação Média e Tecnológica (SEMTEC) e pareceristas do Conselho Nacional de Educação (CNE) - procuraram caracterizar os conhecimentos filosóficos a serem trabalhados nas escolas como temas transversais. Embora os documentos não excluam o ensino disciplinar, a presença transversal nos currículos garantiria, em tese, o cumprimento da LDB quanto à necessidade de domínio de conhecimentos de filosofia, sem a necessidade de uma disciplina específica.

Dentre os argumentos mais utilizados para defender o ensino transversal da filosofia, em oposição a um ensino disciplinar, três são recorrentes. $\mathrm{O}$ primeiro diz respeito à precariedade da formação de professores de filosofia para o ensino médio em âmbito nacional. Embora existam cursos de licenciatura em filosofia na grande maioria dos estados, ainda há, de fato, muito o que aprimorar na busca de uma formação qualificada dos professores, mesmo nos estados com melhores índices econômicos e educacio- 
nais. Permanece, entretanto, a controvérsia em torno da pertinência da adoção do ensino disciplinar. Quem a defende considera que a medida pode ser indutora de processos de melhoria da formação docente; quem a critica, enfatiza a suposta irresponsabilidade que significaria, de imediato, colocar em sala de aula um grande número de professores aparentemente despreparados para a função. Outro argumento, fortemente vinculado ao primeiro, diz respeito aos problemas que a obrigatoriedade da disciplina em nível nacional poderia trazer aos estados e seus sistemas de ensino, em especial em termos de investimentos. Por fim, há os que se posicionam contrariamente à inserção da disciplina por criticarem o modelo disciplinar de escola. Estes defendem que a inserção de mais uma disciplina escolar é uma medida infeliz, particularmente no caso da filosofia. A partir desse ponto de vista, se a filosofia deve ser um exercício de pensamento crítico, ou lúdico, ou que vise à autonomia etc., transformá-la em "matéria escolar” seria sujeitá-la aos rituais e tratamentos pedagógicos que os estudantes costumam identificar, precisamente, como o oposto da crítica, do prazer, da autonomia etc.

Por cerca de três anos tramitou na Câmara e no Senado Federal um projeto de lei complementar que substituía o citado artigo 36 da LDB, instituindo a obrigatoriedade das disciplinas Filosofia e Sociologia nos currículos do ensino médio. Após aprovação nestas duas instâncias do Poder Legislativo Federal, o projeto foi vetado em outubro de 2001 pelo então presidente Fernando Henrique Cardoso. Os argumentos que sustentaram o veto foram basicamente dois, já mencionados: a) a inclusão das disciplinas de Filosofia e Sociologia implicaria incremento orçamentário impossível de ser arcado pelos estados e municípios; b) não haveria suficientes professores formados para fazer frente às novas exigências da obrigatoriedade da disciplina.

Diante destas razões, tem-se argumentado que ambas são falaciosas: a) a inclusão das novas disciplinas não implica necessariamente aumento orçamentário, uma vez que o que está em jogo é um remanejamento da carga horária curricular e não seu aumento; b) existe um número significativo de pessoas já formadas e a presença disciplinar da filosofia na grade curricular tenderia a aumentar o interesse das pessoas e das instituições por uma formação adequada.

Além disso, um dos argumentos mais importantes do movimento em favor da inserção da filosofia como disciplina no currículo é a suposi- 
ção de que somente o ensino disciplinar garantiria uma introdução verdadeiramente consistente e sistemática dos jovens no âmbito da reflexão filosófica; ainda mais se levadas em conta as próprias objeções daqueles que defendem um ensino transversal, a saber: a precariedade da formação dos professores e as limitações financeiras dos estados. Em uma escola ainda fortemente disciplinar, relegar a filosofia à transversalidade tenderia não apenas a diluir a especificidade da filosofia em meio aos estudos "que realmente contam no currículo" como também aprofundar a situação de precariedade que se imputa aos professores de filosofia no país, na medida em que poderia servir para reforçar a dispensa de contratação, por parte dos estados, de profissionais especializados para a função.

Baseados nesses argumentos, os que defendem a presença disciplinar da filosofia continuam batalhando. Em 24 de junho de 2003, teve lugar uma audiência pública sobre a volta da filosofia e da sociologia ao currículo do ensino médio, realizada pela Comissão de Educação, Cultura e Desporto da Câmara dos Deputados, com a presença de Sr. Antônio Ibañez Ruiz (secretário de Educação Média e Tecnológica do Ministério da Educação - SEMTEC); Sr. Antônio Prado (presidente da Federação Nacional dos Sociólogos); e Sr. Igor Bruno de Freitas Pereira (presidente da União Brasileira dos Estudantes Secundaristas - UBES). Tramita, ainda, no Congresso Nacional, um projeto de lei com as mesmas características do anteriormente vetado, com apoio do atual Ministério da Educação. Confiram-se alguns dos argumentos apresentados na justificativa do citado projeto de lei, atualmente tramitando na Câmara dos Deputados, que faz referência à Declaração de Paris pela Filosofia (Brasil, 2003, p. 2-3):

A inclusão da Filosofia e da Sociologia no currículo do Ensino Médio é uma medida necessária para a consolidação dos objetivos e finalidades da educação básica. Tal medida fundamenta-se no entendimento de que a Filosofia e a Sociologia possuem estatutos próprios e, enquanto disciplinas, são análogas a qualquer outra, com saberes, corpo teórico, lógicas internas, técnicas e terminologias específicos. Delas, os alunos têm muito que aprender e assimilar. A defesa da inclusão da Filosofia e da Sociologia no currículo não é recente. $\mathrm{E}$, da mesma forma que se evidencia o escândalo teórico e político da sua retirada do núcleo comum do currículo (recorde-se a Lei n. 5.692, de agosto de 1971, que tenta, de forma ilegítima, substituir a Filosofia e a Sociologia introduzindo, respectivamente, as disciplinas de Educação Moral e Cívica e Organização Social e Política do Brasil), também se percebe a correlação de seu ensino com o avanço do processo democrático, tornando-se imperativo restaurar um 
pensamento crítico em educação. Compreende-se que seja assim, pois não há propriamente ofício filosófico (nem sociológico, mutatis mutandis) sem sujeitos democráticos e não há como atuar no campo político e cultural, consolidar a democracia, quando se perde o direito de pensar, a capacidade de discernimento, o uso autônomo da razão. Quem pensa opõe resistência.

Mais à frente:

A presença da Filosofia e da Sociologia no currículo poderá contribuir para a ressignificação da experiência do aluno, tanto de seu posicionamento e intervenção no meio social, enquanto futuro construtor do processo histórico, como de leitura e constituição de um olhar mais consistente sobre a realidade. Esses planos se entrelaçam e voltam-se ao sujeito da aprendizagem, podendo ampliar sua visão de mundo, enriquecer sua existência, renovar seus projetos, tecer sua sociabilidade, fazer sentir sua liberdade.

Em resumo, a presença disciplinar da filosofia no ensino médio fica, na prática, a critério de cada estado da Federação. Em vários estados houve mudanças recentes. A partir de 1979, com a progressiva redemocratização do país, vários estados passaram a adotar a filosofia como disciplina no ensino médio da rede pública, por meio de leis estaduais ou recomendações das secretarias estaduais de educação. Com a nova legislação de finais dos anos de 1990, alguns estados passaram a adotar os PCNEM como orientação para o ensino nas escolas. Em alguns casos, há indícios de uma defesa da transversalidade; noutros, pode-se identificar, ao contrário, o início de um processo em direção à adoção da filosofia como disciplina.

\section{Um mapa algo mais detalhado}

A duração dos cursos de filosofia é, na maioria dos estados, de um ano ao longo do ensino médio. Há a indicação de duas unidades da Federação (Distrito Federal e Mato Grosso do Sul) que mantêm a filosofia como disciplina nos três anos do ensino médio com carga horária de duas horas semanais. Em alguns estados (como Espírito Santo, Mato Grosso, Paraíba e Pará), há indicativos de uma progressiva expansão do ensino para duas ou três séries. Não há informações precisas sobre o tipo de trabalho realizado com base na proposta de transversalidade dos PCN, seja no ensino fundamental, seja no médio, e, portanto, não é possível determinar sua duração. Pode-se discriminar do seguinte modo a duração dos cursos de filosofia no ensino médio: 
Altair A. Fávero, Filipe Ceppas, Pedro E. Gontijo, Sílvio Gallo \& Walter O. Kohan

- Unidades da Federação que adotam a disciplina, em toda a rede pública, com ao menos duas horas semanais durante mais de um ano/série: 2 (Distrito Federal e Mato Grosso do Sul).

- Estados que adotam a disciplina, em toda a rede pública, com ao menos duas horas semanais durante um ano/série: 13 (Acre, Alagoas, Amazonas, Bahia, Goiás, Maranhão, Pará, Piauí, Rio de Janeiro, Roraima, Santa Catarina, Sergipe e Tocantins).

- Estados que adotam a disciplina de modo opcional na rede pública, com ao menos duas horas semanais: 7 (Espírito Santo, Paraíba, Paraná, Pernambuco, Rio Grande do Norte, Rio Grande do Sul e Minas Gerais). Nesses estados, a carga horária varia muito. Em Pernambuco, por exemplo, algumas escolas que oferecem a disciplina o fazem, geralmente, no primeiro ano, com duas horas semanais, ao passo que outras oferecem a disciplina também no $2^{\circ}$ ano.

Embora não seja possível descrever a situação de todos os estados, vale indicar casos significativos, acompanhando as tendências regionais:

\section{Centro-Oeste}

No Distrito Federal, por resolução da Secretaria de Educação, a filosofia é oferecida como disciplina nas três séries do ensino médio, desde 2000, com duas horas semanais. Existem cerca de 80 escolas públicas com ensino médio e aproximadamente 100 mil alunos. $\mathrm{Na}$ rede privada, não são todas as escolas que oferecem filosofia.

Em Goiás, o ensino de filosofia é obrigatório em duas séries do ensino médio.

Em Mato Grosso, a filosofia é componente curricular juntamente com a sociologia desde 1998, porém não há uma determinação quanto a sua presença em um ou mais anos do ensino médio, nem quanto à carga horária semanal da disciplina. As escolas devem seguir os Parâmetros Curriculares Nacionais. Geralmente segue-se uma abordagem histórica.

Em Mato Grosso do Sul, o ensino de filosofia atualmente ocorre em duas aulas semanais nos três anos do ensino médio, juntamente com o 
ensino de sociologia em uma disciplina denominada Ciências Sociais. A divisão de conteúdos está de acordo com o período histórico (Antiguidade Clássica, Idade Média, Idade Moderna, Contemporânea).

\section{Nordeste}

$\mathrm{Na}$ Bahia, apesar de o ensino de filosofia ser opcional, a maioria das escolas oferece a disciplina no $1^{\circ}$ ano, com uma aula por semana. De 1996 a 1999, a filosofia era ensinada em duas aulas por semana. Com a reforma de 1999, que diminuiu o número de aulas diárias de cinco para quatro no período noturno, a filosofia passou a ser oferecida com uma aula por semana. Em muitas escolas, o mesmo aconteceu também no período diurno.

No Piauí, em 1999, a disciplina foi inserida no ensino médio, por orientação do Conselho Estadual de Educação (SEED/PI). A partir de 2000, a disciplina passou a constar como disciplina obrigatória na matriz curricular do ensino médio das escolas públicas estaduais, na $1^{\text {a }}$ série, com duas aulas por semana. Em Teresina, desde 1986 muitas escolas particulares também oferecem a disciplina Filosofia. Em pesquisa realizada no ano de 2000, o Núcleo de Estudos sobre o Ensino de Filosofia (NEFI), de Teresina, constatou um universo aproximado de 30 a 40 escolas particulares que adotam a disciplina, num universo total de 250 escolas particulares (Carvalho \& Cabral, 2003). Um projeto de lei do vereador Anselmo Dias foi aprovado por unanimidade na Câmara Municipal de Teresina, estabelecendo a obrigatoriedade do ensino de filosofia no nível fundamental. O projeto foi vetado, em 1999, pelo prefeito, que alegou implicações de ordem econômica.

Em Alagoas, a filosofia foi introduzida como disciplina obrigatória em duas séries do ensino médio, mas aguarda regulamentação de carga horária e conteúdo programático. Nos estados do Maranhão, Sergipe e Tocantins, a disciplina é oferecida em ao menos um ano do ensino médio, sendo que, no Tocantins, ela é oferecida em conjunto com sociologia, em uma única disciplina. Nos estados da Paraíba, Pernambuco e Rio Grande do Norte, a disciplina é opcional.

\section{Norte}

No Acre, a disciplina Filosofia é oferecida no ensino médio, e perfaz 120 horas ao ano. No Amazonas, a filosofia faz parte, desde a década de 1980, do núcleo de disciplinas diversificadas e é oferecida no $3^{\circ}$ ano, per- 
fazendo um total de 80 horas por ano. No estado do Pará, a disciplina é oferecida em toda a rede pública na $1^{a}$ série do ensino médio. Em Roraima, a disciplina também faz parte do núcleo de disciplinas diversificadas, e é oferecida no $2^{\circ}$ ano do ensino médio, perfazendo 40 horas/ano.

\section{Sudeste}

Em Minas Gerais, a Constituição Estadual de 1989, em seu artigo 195, determina o ensino de filosofia e de sociologia no ensino médio, mas o artigo não foi regulamentado e tem permitido interpretaçōes diversas por parte do Conselho Estadual de Educação (CEE). Entre 1989 e 1995, a filosofia foi ensinada em toda a rede pública, em uma das séries, com carga horária variável de escola para escola. Após a aprovação da LDB, em 1996, as escolas vêm reduzindo a carga horária dessa disciplina e muitas a retiraram do currículo. A não-regulamentação do artigo 195 da Constituição Estadual tem permitido às escolas públicas e particulares de ensino médio não oferecerem a disciplina, adotando projetos, temas transversais ou trabalho interdisciplinar. Na região de Uberlândia, a maioria das escolas de ensino médio, tanto públicas quanto privadas, conta com a disciplina de Filosofia durante pelo menos um ano, posto que há dez anos a Universidade Federal de Uberlândia incluiu a prova de filosofia em seus exames vestibulares, para ingresso nos cursos daquela instituição.

No Rio de Janeiro, a Câmara de Ensino de $2^{\circ}$ Grau aprovou, em 31 de janeiro de 1980, o Parecer n. 49/80 que incluía a filosofia na rede pública e privada do estado. $\mathrm{Na}$ rede pública, segundo resolução estadual de 2000 (Resolução SEE n. 2.284/2000), a filosofia ocuparia duas horas semanais no $1^{\circ}$ ano e uma hora semanal no $2^{\circ}$ ano dos cursos diurnos; e duas horas semanais nos $1^{\circ}$ e $2^{\circ}$ anos dos cursos noturnos. Mas, de fato, a disciplina ocupa somente duas horas semanais no $1^{\circ}$ ano em todos os turnos e a situação dos professores é precária, como em várias partes do país, sendo vários deles formados em outras habilitaçōes que não filosofia, deslocados para ministrar a disciplina via "gratificação por lotação prioritária" (GLP). Já o Colégio Pedro II, ${ }^{2}$ que atende a cerca de 15 mil estudantes da cidade do Rio de Janeiro (nos níveis fundamental e médio), oferece a disciplina com duas horas semanais nas $1^{\circ}$ e $2^{\circ}$ séries do ensino médio, além de disciplinas filosóficas eletivas.

No Estado de São Paulo, a filosofia foi ensinada entre 1985 e 1996 como disciplina opcional: a direção da escola deveria optar por duas discipli- 
nas, entre filosofia, psicologia e sociologia. Após 1997, com a LDB, a obrigatoriedade desta opção caiu, posto que a Secretaria Estadual de Educação compreende que o trabalho interdisciplinar e/ou transversal dá conta das prerrogativas da LDB. À semelhança do quadro no nível federal, um projeto de lei aprovado na Assembléia Legislativa que tornava filosofia e sociologia obrigatórias foi vetado pelo governador do estado em 2002. Hoje, muitas escolas públicas e privadas oferecem a disciplina Filosofia no ensino médio, com diferentes cargas horárias, predominando aquelas que oferecem a disciplina com duas horas-aula, em uma das séries desse nível de ensino. Também na educação fundamental há diversas escolas que oferecem filosofia, aqui com predomínio das particulares.

\section{Sul}

No Rio Grande do Sul e no Paraná, a disciplina é opcional. No Paraná, há um projeto de lei que determina a obrigatoriedade da filosofia e da sociologia no ensino médio, de autoria do deputado Ângelo Vanhoni, em tramitação na Assembléia Legislativa. Várias escolas particulares de ensino fundamental oferecem a disciplina Filosofia nesse estado. No Rio Grande do Sul, o deputado Giovani Cherini possui um projeto de lei para tornar a disciplina obrigatória, mas este ainda não foi submetido a uma votação na Assembléia Legislativa estadual.

O Estado de Santa Catarina colocou a filosofia como disciplina obrigatória em ao menos um ano do ensino médio, por meio da aprovação, pela Assembléia Legislativa estadual, de um projeto de lei proposto pelo deputado Pedro Uczai.

\section{A filosofia nos demais níveis de ensino}

Como complemento necessário à situação da filosofia no nível médio, vale indicar algumas características bem gerais da inserção da filosofia nos demais níveis de ensino.

\section{Ensinos infantil e fundamental}

Desde 1985, com a chegada ao Brasil do programa de "Filosofia para Crianças", criado por Mathew Lipman, ${ }^{3}$ algumas escolas - em sua 
maioria particulares - adotam a filosofia como disciplina em seus currículos do ensino fundamental. No ensino infantil há experiências sistemáticas com a filosofia pelo menos desde 1995. Recentemente, alguns poucos municípios, particularmente na Bahia (Ilhéus, Una, Itabuna) e no Mato Grosso (Cuiabá), estabelecem a obrigatoriedade do ensino de filosofia na rede pública no nível fundamental. Há também universidades e escolas que desenvolvem pesquisas e metodologias próprias para o ensino de filosofia nos níveis infantil e fundamental. ${ }^{4}$

De modo geral, no ensino fundamental há registros de escolas privadas trabalhando com filosofia em quase todos os estados e das públicas em alguns deles (Distrito Federal, Rio de Janeiro, Mato Grosso, São Paulo, Bahia). Por exemplo, em Itabuna, quarta maior cidade da Bahia, há filosofia no ensino fundamental, de $5^{\text {a }}$ à $8^{a}$ série, em todas as escolas do município.

Os Parâmetros Curriculares Nacionais para o Ensino Fundamental (PCNEF), publicados em 1998, prevêem a adoção de temas transversais nesse nível de ensino, notadamente nas áreas de ética e cidadania. Também os Parâmetros Curriculares Nacionais para o Ensino Médio (PCNEM), de 1999, prevêem que conteúdos de filosofia devam ser trabalhados na forma de temas transversais, embora, nestes, a filosofia apareça como uma disciplina da área de "Ciências Humanas e Suas Tecnologias". Estas disposições especificam o que já a LDB havia determinado (Seção IV, artigo 36, parágrafo 10): que os estudantes, ao final do ensino médio, demonstrem "dominar os conhecimentos de filosofia e de sociologia necessários ao exercício da cidadania”.

Por vezes, as noções de transversalidade e interdisciplinaridade são tratadas como sinônimas, embora se possa ter transversalidade sem que haja interdisciplinaridade, em algum sentido mais interessante que a mera coexistência de conteúdos de áreas diferentes ou afins. Todavia, os PCNEM também apresentam propostas de ensino interdisciplinar para as áreas comuns. No caso da filosofia, a área engloba, ainda, história, geografia, sociologia, antropologia e política. Ainda não há dados concretos para avaliar a efetivação ou não de programas adotados a partir da promulgação da LDB e da edição dos PCN, muito menos seu alcance até o momento. Inspiradas ou não na legislação, existem algumas experiências em escolas isoladas que envolvem a interdisciplinaridade, sobretudo no nível da educação fundamental, principalmente com os temas transversais de ética e cidadania. 


\section{Nivel superior}

No nível superior, distribuídos por todas as unidades da Federação, existem ao menos 56 cursos de filosofia nas universidades, públicas e particulares, incluindo bacharelado e licenciatura. ${ }^{5}$ Por meio de disciplinas como "Introdução à Filosofia", "Lógica" ou mesmo "Metodologia Científica" (esta última freqüentemente a cargo dos departamentos de filosofia), a filosofia é matéria comum do "ciclo básico" da maioria das universidades, isto é, compõe disciplinas que são oferecidas a todos os cursos universitários. Há, ainda, em muitos departamentos de educação, a disciplina "Filosofia da Educação" (e/ou outras similares) para todos os estudantes dos diversos cursos de licenciatura. ${ }^{6}$ Nos Institutos Superiores de Formação para o Magistério, encontramos a presença regular da disciplina "Filosofia da Educação" e a presença eventual de outras disciplinas como "Introdução à Filosofia" ou "Lógica".

Em nível de pós-graduação, existem programas consolidados de mestrado e doutorado em filosofia, a maioria concentrada nas regiōes Sul e Sudeste. Há também programas de especialização em diversas universidades do país, alguns deles específicos sobre o ensino de filosofia. ${ }^{7}$

\section{Notas para um balanço deste espaço}

Concluindo este tópico, queremos apresentar um balanço geral, avaliando os pontos positivos e os inconvenientes da atual configuração do ensino da filosofia no ensino médio brasileiro. Infelizmente, em razão da ausência de dados confiáveis sobre a situação na maioria dos estados, é quase impossível determinar com segurança as vantagens e desvantagens nas diferentes configurações institucionais e curriculares do ensino de filosofia. Entretanto, professores do ensino médio e pesquisadores de todo o país vêm se organizando e participando de eventos comuns, o que já constitui um grande avanço em um país de dimensões continentais como o Brasil. Muitos deles, em meio aos obstáculos e às críticas, trazem relatos e análises por vezes otimistas do alcance do ensino de filosofia em suas localidades. No caso dos estados que não adotam a disciplina como parte do currículo, a indicação de trabalho com temas filosóficos por meio de temas transversais não parece ter gerado, até o presente momento, qualquer resultado significativo.

Os inconvenientes da atual organização institucional são muitos e graves, sobretudo no ensino médio dos estados que não possuem a disciplina em seus currículos. Com a filosofia ausente do currículo, dificilmente o esta- 
do ou o município abrem concurso para contratar um professor dessa área. Assim, o trabalho com temas filosóficos, como a ética, por exemplo, acaba ficando como prerrogativa de professores de outras áreas e disciplinas, na maioria das vezes despreparados para trabalhar com filosofia. O resultado é que não se efetiva, na prática, um ensino filosófico. No contexto da presença da filosofia no currículo, a situação também é crítica. São raríssimos os concursos para a contratação de professores de filosofia, o que revela a desvalorização, na prática, do ensino de filosofia diante das outras disciplinas, a despeito da legislação. Dentre aqueles que estão no sistema, existe um enorme contingente de professores de filosofia sem formação em filosofia. A remuneração dos professores da rede pública já é, de modo geral, notadamente baixa, incompatível com a responsabilidade e o esforço exigidos pela profissão. A pequena carga horária da filosofia, via de regra, apenas dois tempos por semana, prejudica ainda mais o professor. Por fim, a filosofia no ensino médio sofre, por tabela, a pressão exercida pelo exame de acesso ao ensino superior, o vestibular, que coloca um peso muito grande nas matérias "tradicionais", constrangendo os interesses e a atenção das escolas, dos professores e estudantes e, muitas vezes, transformando a filosofia numa disciplina ornamental.

No caso do ensino fundamental, a multiplicação das tentativas de inserção da filosofia como espaço de reflexão acessível, também, às crianças e, principalmente, a abertura para a diversidade dessas iniciativas parecem contar, em si mesmas, como fato positivo. No ensino superior, há a consolidação de programas e linhas de pesquisa, acompanhada de uma crescente profissionalização. Aspectos positivos desse processo são: o maior pluralismo e a superação de configurações conceituais por demais esquemáticas ou doutrinárias; crescimento significativo da produção filosófica nacional de qualidade, assim como de traduções; e uma possível maior abertura da filosofia para a interlocução com âmbitos da sociedade e da cultura antes ignorados ou desvalorizados, como a própria dimensão do ensino de filosofia na educação básica, que, em grande medida, permanece em segundo plano.

II. Programas, métodos e materiais de apoio utilizados no ensino da filosofia em nível médio

Os Parâmetros Curriculares Nacionais para o Ensino Médio (PCNEM) não são programas oficiais obrigatórios, mas sugestões de orga- 
nização curricular visando a atender certas prerrogativas legais. No caso da filosofia, seus conteúdos estão previstos nos chamados "temas transversais", que devem atravessar os conteúdos das disciplinas e áreas curriculares. No caso do ensino fundamental, o tema transversal de ética está previsto para os $3^{\mathrm{o}}$ e $4^{\mathrm{o}}$ ciclos $\left(5^{\mathrm{a}}\right.$ e $6^{\mathrm{a}}$ séries e $7^{\mathrm{a}}$ e $8^{\mathrm{a}}$ séries). No caso do ensino médio, também se prevê a inclusão da ética como tema transversal.

Os PCNEM prevêem a filosofia como disciplina, no contexto da grande área Ciências Humanas e suas Tecnologias, e o texto elaborado pelos autores responsáveis pela área de filosofia é reputado como de boa qualidade. Como se trata de uma proposta baseada no conceito de competências (do debate, da argumentação, da leitura e da escrita etc.), o texto não elenca conteúdos e objetivos específicos a serem trabalhados. Como ilustração, reproduzimos, a seguir, as "competências e habilidades a serem desenvolvidas em filosofia", segundo os PCNEM:

Representação e comunicação: ler textos filosóficos de modo significativo; ler, de modo filosófico, textos de diferentes estruturas e registros; elaborar por escrito o que foi apropriado de modo reflexivo; debater, tomando uma posição, defendendo-a argumentativamente e mudando de posição em face de argumentos mais consistentes.

Investigação e compreensão: articular conhecimentos filosóficos e diferentes conteúdos e modos discursivos nas Ciências Naturais e Humanas, nas Artes e em outras produções culturais.

Contextualização sociocultural: contextualizar conhecimentos filosóficos, tanto no plano de sua origem específica quanto em outros planos: o pessoal-biográfico; o entorno sociopolítico, histórico e cultural; o horizonte da sociedade científico-tecnológica. (Brasil, 1999, p. 125)

Não é possível determinar com precisão os domínios ou campos mais trabalhados no ensino de filosofia no nível médio, dada a inexistência de um programa oficialmente definido e de pesquisas, em nível nacional, a esse respeito. A partir de nosso levantamento, podemos dizer que os temas mais presentes nos programas preparados pelos professores são: cultura geral; filosofia antiga (em especial, o surgimento da filosofia); ética; história da filosofia; teoria do conhecimento; e política. Das discussões em nível nacional e dos trabalhos apresentados em encontros ou publicados, podese inferir que a filosofia no ensino médio se resume, na maioria dos casos, a debates em torno de temas atuais, com o auxílio de referências filosóficas, o que ajuda a especificar o que se está entendendo por "cultura geral". ${ }^{8}$ 
A partir de depoimentos de professores de vários estados, pode-se dizer que os filósofos mais comumente trabalhados pelos professores em seus programas de ensino são: Sócrates, Platão, Aristóteles, Descartes, Sartre, Kant e Marx. No ensino fundamental e no ensino médio, em geral, não se faz referência a filósofos brasileiros ou mesmo latino-americanos. No ensino superior, tampouco essa área é muito explorada. Já houve centros de estudos de filosofia brasileira no Espírito Santo, em Londrina, no Paraná e no Rio de Janeiro, mas que se encontram hoje desativados. Alguns cursos superiores de filosofia incluem disciplinas de Filosofia no Brasil e/ou Filosofia Latino-americana; nesses casos, predominam Vicente Ferreira da Silva, João Cruz Costa, Sylvio Romero, Miguel Reale e a linha de "filosofia da libertação", a partir dos trabalhos de Enrique Dussel. Mas, apesar deste trabalho desenvolvido nas academias, na educação básica os professores restringem-se aos filósofos europeus.

Quanto à estruturação dos conteúdos, os programas de filosofia para o ensino médio, em geral, são articulados segundo quatro grandes modelos:

1) Por temas: nesse caso, predominam temáticas como conhecimento, verdade, valores, cultura, ideologia, alienação, sexualidade, condição humana, finitude, liberdade, poder, política, justiça, arte, meios de comunicação.

2) Por dominios ou campos filosóficos: aqui aparecem prioritariamente os campos já citados anteriormente, como cultura geral, filosofia antiga, ética, história da filosofia, teoria do conhecimento e política.

3) Por problemas: nesse caso, os conteúdos são articulados em torno de problemas filosóficos, entre os quais o problema do ser, do conhecer, do agir, da ciência etc.

4) Por critérios cronológicos: aqui o referencial passa a ser a história, sendo que predominam as filosofias antiga e moderna.

Muitos professores costumam seguir um livro didático, sendo que os mais freqüentes são: Filosofando, de Maria Lúcia de Arruda Aranha e Maria Helena Pires Martins, e Convite à filosofia, de Marilena Chaui. Nesses casos, é o próprio manual que pauta o trabalho em sala de aula, definindo inclusive o programa do professor. De forma bastante geral, os programas de filosofia tendem a ser organizados por meio de temas filosóficos. No entanto, como não há uma determinação legal, podemos encontrar, 
também, programas organizados em torno de conteúdos de história da filosofia e em torno de problemas filosóficos. Mesmo no caso dos programas organizados por temas, a diversidade é muito grande. Uma estrutura mais complexa daquilo que de fato acaba sendo o ensino de filosofia poderia ser exemplificada com conjuntos de temas predominantemente utilizados em escolas do estado de São Paulo, a partir de um trabalho feito pela Secretaria Estadual de Educação na década de 1980, quando da reintrodução opcional da disciplina nos currículos:

A filosofia e os demais conhecimentos: senso comum; mito e religiāo; $c$ ência; o conhecimento filosófico; a ideologia.

A condição humana: a cultura; a técnica e a tecnologia; o homem e o trabalho; trabalho e alienação.

A ação humana: os valores; ética $x$ moral; distintas concepções éticas; a liberdade; a sexualidade.

Política e cidadania: cidadania e democracia; concepçôes politicas na história; o liberalismo e o socialismo.

Estética e comunicação: $o$ belo nas artes; arte e sociedade; a televisão, o cinema e a sociedade contemporânea.

A correspondência desses temas ao trabalho efetivo de sala de aula requer, entretanto, inúmeras mediações, cuja análise e compreensão dependem de pesquisas empíricas a serem realizadas. Se o trabalho com temas pode configurar, para muitos, uma proposta válida, ou mesmo a mais adequada em se tratando de filosofia com adolescentes, as condiçóes de ensino podem levar o trabalho efetivamente realizado a distanciar-se radicalmente de um modelo minimamente satisfatório, pela ausência de um engajamento reflexivo passível de ser identificável com filosofia.

Em termos de métodos, técnicas e materiais de ensino, de longe o método mais utilizado é o da aula expositiva, muitas vezes com o apoio do debate ou de trabalhos em grupo. Com menor frequiência, utilizam-se de seminários, nos quais os alunos preparam uma apresentação em grupo; estudos de textos e pesquisa bibliográfica; uso de música, poesia, literatura e filmes em vídeo para sensibilização quanto ao tema a ser desenvolvido. A maioria dos professores adota o livro didático (manuais), ou compõe apostilas com formato semelhante ao do livro didático. Muitas vezes o trabalho limita-se à interpretação e contextualização de fragmentos de alguns filósofos, ou de debate sobre temas atuais, confrontado com pequenos textos 
filosóficos. Mais recentemente, muitos professores passaram a adotar uma metodologia mais participativa na qual os alunos trocam opiniōes sobre os assuntos em debate. Os professores costumam utilizar-se de músicas e de filmes em vídeo para suscitar a análise e o debate em torno de determinados temas. Há, também, a discussão a partir de crônicas, matérias de jornal ou revistas; organização de júri simulado para discutir certo tema; trabalhos com músicas e vídeos; trabalhos de grupo. Ainda, em muitos casos, existe a introdução de técnicas de relaxamento, e outras práticas que aproximam a aula de filosofia de uma "terapia coletiva". É pouco freqüente a leitura de textos de filósofos, de primeira mão.

Em termos gerais, podemos afirmar que o ensino de filosofia feito no Brasil ainda é bastante tradicional, muito embora tenha avançado com relação a um ensino descontextualizado da história da filosofia, voltandose mais para temas e problemas filosóficos. Pode-se citar como "novidade metodológica" sobretudo a inclusão, desde 1985, de princípios e técnicas do programa de "Filosofia para Crianças" de Matthew Lipman, que se estende até a educação média. Concordemos ou não com seus fundamentos e práticas, é inegável que sua introdução contribui para uma perspectiva mais ativa no ensino da filosofia. Hoje, vemos professores que, mesmo no ensino superior, procuram utilizar uma metodologia mais dialógica, participativa e cooperativa.

É possível verificar que esses professores de filosofia buscam um ensino mais ativo nos diversos níveis, que não fique circunscrito à análise e explicação de textos, até recentemente predominante, por influência da escola francesa. Em geral a metodologia de Lipman é aplicada nas escolas sob supervisão do Centro Brasileiro de Filosofia para Crianças (CBFC) ou de seus afiliados. Os professores são treinados pelos monitores para utilização do programa, que prevê a leitura das novelas filosóficas, o diálogo investigativo, na sala de aula, a partir das situaçóes postas pelo texto e a busca de soluçôes que privilegiem o desenvolvimento do raciocínio (cf. Kohan, 2000, passim).

Numa perspectiva mais analítica, podemos afirmar que o aspecto mais positivo que encontramos nas metodologias hoje utilizadas no Brasil para o ensino da filosofia na educação média é a abertura. $\mathrm{Na}$ medida em que não existem programas obrigatórios, também não há manuais ou técnicas obrigatórias. Sendo assim, o professor de filosofia pode usar criativamente seus conhecimentos e suas capacidades. Mais que vantagem ou desvantagem, importa perceber os esforços dos professores de filosofia em 
torno de determinadas práticas e métodos sob a luz das condições de ensino, dos desafios e objetivos que se constroem em torno do ensino de filosofia.

Talvez se possa afirmar que a precariedade das condições força os professores a buscarem caminhos para o trabalho da filosofia em sala de aula que sejam, de fato, significativos para os estudantes. Assim, abertura não significa apenas liberdade de trabalho pela ausência de diretrizes oficiais obrigatórias, mas também, e sobretudo, a possibilidade de que os professores, com todos os problemas enfrentados, e talvez em função mesmo desses problemas, aproximem-se dos estudantes e consigam perspectivar o trabalho com a filosofia de modo que superem resultados extremos e pouco expressivos, como o mero exercício do confronto de opiniōes, por um lado, e o mero estudo de conteúdos, por outro.

Aspectos dessa abertura de que falamos, tal como ela se dá no contexto atual, também configuram inconvenientes. $\mathrm{O}$ pequeno número de instâncias de formação continuada, a ausência de suportes didáticos mais bem definidos e a eventual formação deficiente, somadas à ausência de instâncias que estimulem um trabalho crítico-reflexivo sobre a prática, tudo isso conspira para obstaculizar um trabalho efetivamente filosófico dos professores junto dos estudantes. Quanto aos suportes didáticos, a maioria dos manuais voltados para o ensino de filosofia no nível médio é inadequada. Mesmo textos de boa qualidade, como o de Marilena de Souza Chaui, talvez o mais prestigiado entre todos os existentes no país, é considerado muito "pesado" pelos professores (tem 440 páginas e um estilo bastante "acadêmico") e pressupõe uma concepção excessivamente clássica da filosofia e de seu ensino.

Em contrapartida, a experiência com o ensino de filosofia no Distrito Federal, contemplada especificamente neste Dossiê, mostra que a simples presença da filosofia não garante uma contribuição significativa desta. Pode representar mais que uma diversidade de experiências, uma uniformidade de desorientação.

Com relação aos PCNEM, talvez o maior inconveniente seja o fato de que sua adoção, por força das conjunções políticas e institucionais locais, muitas vezes dê-se de modos mais ou menos constrangedores, apesar de o documento configurar simples parâmetros, isto é, uma proposta "alternativa” para o ensino. Tanto nos PCNEM como em propostas mais divulgadas para o ensino da filosofia no nível fundamental, existem diversos pontos 
polêmicos que, por vezes, são apresentados menos como pontos a serem discutidos que como princípios a serem seguidos, em prejuízo do necessário processo reflexivo que deve marcar toda e qualquer iniciativa no âmbito do ensino de filosofia.

\section{A formação dos professores de filosofia e seu exercício profissional}

No Brasil, os cursos de graduação em filosofia são organizados em dois níveis: bacharelado (formação do pesquisador) e licenciatura (formação do professor); muitos cursos oferecem as duas habilitações, ficando a critério do estudante a escolha. No caso da licenciatura em filosofia, de modo geral, ela está voltada exclusivamente para a formação do professor de filosofia para o nível médio, sem maior vínculo com os ensinos fundamental ou superior. Para o primeiro, o que há hoje disponível - fora de algumas experiências ainda isoladas em algumas universidades, geralmente em faculdades de educação - é uma formação não reconhecida oficialmente: os treinamentos feitos pelo CBFC e seus afiliados (já existem também centros de filosofia para crianças que se tornaram independentes do CBFC), voltados especificamente para a utilização do programa de Lipman. Para o exercício da docência de filosofia nos cursos superiores, o requisito essencial da formação é a pós-graduação, sendo que as instituições em geral solicitam do docente, minimamente, o título de mestre e, preferencialmente, o título de doutor.

De forma geral, para o ingresso na docência de filosofia no ensino médio exige-se o título de licenciado em filosofia; no entanto há situações em que professores não graduados em filosofia acabam lecionando essa disciplina, atendendo a especificidades da região e da escola. No caso do ensino fundamental, o mais comum é que professores "polivalentes", com graduação em pedagogia, trabalhem também com as aulas de filosofia. Em termos da educação básica, nem todos os professores de filosofia têm formação específica na área. Entre as outras formaçōes encontramos, mais comumente, cursos da área de ciências humanas, como história, ciências sociais, teologia, pedagogia. Com freqüência bem menor, temos professores de filosofia em exercício com formação distinta destas citadas.

No caso das escolas da rede privada, não se exige concurso para ingresso, mas em geral é feito um processo de seleção de professores, por meio de entrevistas, e se exige, com exceções, a licenciatura em filosofia. 
Na rede pública de ensino, a efetivação no cargo depende de concurso público, para o qual é requerida a licenciatura na área. No caso do estado de São Paulo, o último concurso para professores de filosofia aconteceu em meados da década de 1990; em 2003 aconteceu um grande concurso para professores na rede estadual, mas não foram oferecidas vagas para filosofia, posto que ela não existe oficialmente como disciplina obrigatória. No Rio de Janeiro, o estado vem realizando regularmente concursos. Os últimos foram em 1993, 1998 e 2001. Na Bahia, houve um concurso no ano de 2000, com poucas vagas abertas para filosofia. Na cidade de Ilhéus, por exemplo, não abriram vagas, sendo que $40 \%$ dos professores que ensinam filosofia na região não são formados na disciplina. Em todo o estado, as vagas não chegaram a 30. No Distrito Federal, houve concurso em 2000 e em $2001 \mathrm{com}$, respectivamente, 100 e 20 vagas abertas para filosofia. Em 2001, a Secretaria de Educação de Minas Gerais realizou concurso para professores, abrindo 45 vagas para a filosofia. Um dos últimos concursos públicos para professores do ensino médio do Estado do Rio de Janeiro (2001), incluindo todas as áreas, teve 60 mil inscritos, dos quais apenas 2 mil foram aprovados. Nas secretarias de alguns estados, são inúmeras as dificuldades para obter dados mais precisos sobre concursos, situação dos professores na rede, número de vagas etc.

Para o docente de filosofia em atividade, não é exigido nenhum aperfeiçoamento, atualização ou especialização. Muito recentemente, as universidades brasileiras começaram a desenvolver cursos de especialização para professores de filosofia. Foi o caso pioneiro da Faculdade de Educação da Universidade de Brasília, que está sendo seguido por outras instituições. No caso da Região Sudeste, pode-se destacar o trabalho feito pelo Departamento de Filosofia da Universidade Federal de Uberlândia no acompanhamento dos professores de filosofia da educação média, visando à melhor instrumentalização dos estudantes para a prova de filosofia do vestibular. Também os grupos de estudos sobre ensino de filosofia, em geral sediados nas universidades, acabam se tornando importantes centros de aperfeiçoamento e formação continuada para professores, em seu raio de atuação. Vale destacar ainda os programas de pós-graduação, na medida em que cada vez mais professores do ensino médio procuram esses programas como forma de refletir sobre sua prática e aprimorá-la. No entanto, os departamentos de filosofia das principais universidades públicas ainda se encontram afastados desta preocupação. É de se esperar que eles se abram cada vez mais para acolher essa demanda, que tenderá a ser crescente, seja por- 
que se resolva, em nível nacional, a adotar a obrigatoriedade da disciplina Filosofia na educação média; seja em função das recentes propostas de mudanças nas licenciaturas, formuladas pelo Ministério da Educação nos anos de 2001 e 2002 (em especial, os Pareceres CNE/CP n. 009/2001 e CNE/CP n. 21/2001; e a Resolução CNE/CP de 2 de fevereiro de 2002).

\section{Recebido em maio de 2004 e aprovado em junho de 2004}

\section{Notas}

1. Doravante nos referiremos a essa lei apenas por meio da sigla LDB.

2. O Colégio Pedro II foi fundado no Rio de Janeiro em 2 de dezembro de 1837, tendo como modelo os educandários europeus. Durante o fim do Império, na segunda metade do século XIX, e toda a República Velha (1889-1930), o Pedro II era o único estabelecimento de ensino autorizado a outorgar os títulos que permitiam o ingresso em cursos superiores. Hoje, o colégio é uma autarquia federal do Ministério da Educação e é composto por nove unidades, distribuídas em cinco estabelecimentos localizados em diferentes bairros da cidade do Rio de Janeiro.

3. O Centro Brasileiro de Filosofia para Crianças, fundado em 1985, representa o programa Filosofia para Crianças. Oferece cursos de formação e atualização para professores, publicações periódicas, congressos e venda de materiais didáticos. Em Florianópolis existe um centro semelhante, o "Centro de Filosofia. Educação para o Pensar", com programas próprios adotados também em outras regiōes do país.

4. Entre elas merecem destaque grupos localizados nas Universidades de Brasília, Federal de Mato Grosso, Passo Fundo, Estadual de Londrina e Federal de Juiz de Fora.

5. Há uma disparidade entre as informaçôes fornecidas pelo site do Instituto Nacional de Pesquisas Educacionais Anísio Teixeira (INEP), órgão oficial do governo brasileiro para as estatísticas educacionais (http://www.inep.gov.br/), e as informações colhidas informalmente acerca dos cursos universitários de filosofia no país. Segundo o INEP, existem 56 cursos de filosofia nos "institutos superiores de educação", ao passo que uma lista elaborada pela comunidade acadêmica indica a existência de 91 cursos, incluindo cursos de faculdades isoladas ou centros universitários.

6. Pelo menos na Universidade de Brasília e na Universidade Estadual Paulista, faculdades de educação oferecem várias disciplinas na área de filosofia para crianças, eletivas para diversos cursos.

7. Quanto a estes, registram-se experiências bem-sucedidas, por exemplo, na Universidade de Brasília, na Universidade Federal do Paraná, na Universidade de Passo Fundo e na Pontifícia Universidade Católica de São Paulo.

8. Os temas "filosofia antiga" e "ética" concordam, em parte, com os resultados de pesquisa na Universidade Federal de Piauí (Carvalho \& Cabral, 2003), restrita, entretanto, ao universo do ensino de filosofia em Teresina. Nela, os três campos mais trabalhados são "introdução à filosofia” (que, muitas vezes, está centrada no surgimento da filosofia grega), "ética" e "teoria política". 
O ensino da filosofia no Brasil: um mapa das condições atuais

\section{Referências bibliográficas}

ALVES, D.J. A filosofia no ensino médio - ambigüidades e contradições na LDB. Campinas: Autores Associados/FAPESP, 2002.

BRASIL. Parâmetros Curriculares Nacionais: Ensino Médio. Vol. IV, Ciências Humanas e suas Tecnologias, Brasília, DF: Ministério da Educação/Secretaria de Educação Média e Tecnológica, 1999.

BRASIL. Projeto de Lei, 2003. Altera dispositivos do artigo 36 da Lei n. 9.394, de 20 de dezembro de 1996, que estabelece as diretrizes e bases da educação nacional. Brasília, DF: Câmara dos Deputados, 2003.

CAPALBO, C. (Org.). Seminário Nacional sobre a Interdisciplinaridade no Ensino de Filosofia. Rio de Janeiro: UERJ, 1993-1994.

CARTOLANO, M.T. Filosofia no ensino de segundo grau. São Paulo: Cortez, 1985.

CARVALHO, H.B.A.; CABRAL, C.L.O. Ensino de filosofia nas escolas públicas e privadas da zona urbana de Teresina (PI): um diagnóstico exploratório dos níveis médio e fundamental. 2003. (mimeo.)

CEPPAS, F. Formação filosófica e crítica. Adorno e o ensino de filosofia em nível introdutório. 2003. 252 f. Tese (doutorado) - Faculdade de Educação. Pontifícia Universidade Católica, Rio de Janeiro.

CERLETTI, A.A.; KOHAN, W.O. A filosofia no ensino médio. Brasília: Editora da UNB, 1999.

CHAUÍ, M. Ensinar, aprender, fazer filosofia. Revista do ICHL, Instituto de Ciências Humanas e Letras da UFG, GO, v. 2, n. 1, jan./jul. 1982. p. $1-10$.

COMISSÃO DE EDUCAÇÃO, CULTURA E DESPORTO. Câmara dos Deputados. Audiência Pública sobre a volta da filosofia e da sociologia nos currículos de ensino médio. Brasília, DF, 2003. (mimeo.: transcrição do NESEF, UFPR).

COSSUTTA, F. Elementos para a leitura dos textos filosóficos. São Paulo: Martins Fontes, 1994. 
FÁVERO, A.A.; RAUBER, J.J.; KOHAN, W.O. (Org.). Um olhar sobre o ensino de filosofia. Ijuí: Editora da UNIJUí, 2002.

GALLO, S.; KOHAN, W.O. (Org.). Filosofia no ensino médio. Petrópolis: Vozes, 2000.

GALLO, S.; CORNELLI, M.; DANELON, M. (Org.). Filosofia do ensino de filosofia. Petrópolis: Vozes, 2003.

GONTIJO, P.E. Os professores de filosofia no ensino médio regular das escolas públicas do Distrito Federal: práticas e sentidos em construção. 2003. 127 f. Dissertação (mestrado) - Faculdade de Educação. Universidade de Brasília, Brasília.

GUSDORF, G. A filosofia e a universidade. In: A filosofia e o ensino da filosofia. Teses e debates apresentados no Encontro Nacional de Professores de Filosofia. São Paulo: Convívio, 1979. p. 11-64.

HÜHNE, L.M. (Org.). Politica da filosofia no segundo grau. São Paulo: SEAF, 1986.

KOHAN, W.O. Filosofia para crianças. Rio de Janeiro: DP\&A, 2000.

LEOPOLDO E SILVA, F. Por que filosofia no $2^{\circ}$ grau. Estudos Avançados, v. 6, n. 14, São Paulo, IEA/USP, 1992.

LEOPOLDO E SILVA, F. Currículo e formação: o ensino de filosofia. Sintese - Nova_Fase, v. 20, n. 63, Belo Horizonte, 1993.

LIMA, M.A.C. O Ensino de filosofia e suas contradiçôes. Governador Valadares: UNIVALE, 2002.

LIPMAN, M. A filosofia vai à escola. São Paulo: Summus, 1990.

LIPMAN, M.; OSCANYAN, F.S.; SHARP, A.M. A filosofia na sala de aula. São Paulo: Nova Alexandria, 1994.

LISBOA, M. da G.C.; PEREIRA, R.M.B. Idéias educacionais e filosóficas no Brasil, da Colônia à República. Rio de Janeiro/Porto Alegre: Faculdades Reunidas Nuno Lisboa/Edições Est, 1995.

LUCKESI, C.C. Filosofia, filosofar e prática educativa. Em Aberto, Brasília: MEC, ano IX, n. 45, p. 35-43, 1990. 
O ensino da filosofia no Brasil: um mapa das condições atuais

MARNOTO, I. (Org.). Didáctica da filosofia. V. I-II, Lisboa: Universidade Aberta, 1990.

MAUGUÉ, J. O ensino de filosofia: suas diretrizes. Revista Brasileira de Filosofia, São Paulo, v. V, fasc. IV, n. 20, 1955.

MINISTÉRIO DA EDUCAÇÃO. Situação do Ensino de Filosofia nas Escolas Públicas de Ensino Médio. Informe da Secretária de Educação Média e Tecnológica. Brasília, DF, 2003. (mimeo.)

MUCHAIL, S.T. (Org.). A filosofia e seu ensino. Petrópolis/São Paulo: Vozes/EDUC, 1995.

NETO, H.N. (Org.). O ensino da filosofia no segundo grau. São Paulo/ Rio de Janeiro: SOFIA/SEAF, 1986.

PIEPER, J. Que é filosofar? Que é acadêmico? São Paulo: EPU, 1981.

PIOVESAN, A.; EIDT, C.; GARCIA, C.B.; HEUSER, E.M.D.; FRAGA, P.D. (Org.). Filosofia e ensino em debate. Ijuí: Editora da UNIJUí, 2002.

ROLLA, A.B.M.; NETO, A.S.; QUEIROZ, I.P. (Org.). Filosofia e ensino: possibilidades e desafios. Ijuí: Editora da UNIJUí, 2003.

SABOIA, B. A ditadura brasileira e o ensino da filosofia. São Luís: Editora da UFMA, 2001.

SALMAN, D.H. O lugar da filosofia na universidade. Petrópolis: Vozes, 1969.

SILVEIRA, R.J.T. Matthew Lipman e a filosofia para crianças - três polêmicas. Campinas: Autores Associados, 2003.

WARNOCK, M. Os usos da filosofia. São Paulo: Papirus, 1994. 
APÊNDICE

\section{Associações de apoio ao ensino da filosofia}

Embora não exista nenhuma associação em nível nacional que promova e aperfeiçoe o ensino da filosofia, há muitas associações e grupos locais e/ou regionais que procuram fazê-lo. Ademais, a partir do I Congresso Brasileiro de Professores de Filosofia (Piracicaba, SP, outubro de 2000), foram organizadas três edições dos Fóruns Sul e Centro-Oeste de Ensino de Filosofia, e uma edição do Fórum Sudeste de Ensino de Filosofia. As principais associações, instituições e grupos em torno do ensino de filosofia hoje atuantes são:

Apoio ao Ensino de Filosofia: projeto de extensão da Universidade Estadual de Londrina, Paraná, ativo desde 1997. Propõe diversas ações tendentes a subsidiar a prática da filosofia com crianças e jovens em escolas públicas na cidade de Londrina, Paraná.

Associação de Professores de Filosofia do Alto Tietê (APROFAT): com sede em Suzano/SP, existe desde 2002 e reúne professores de filosofia das cidades de Suzano, Itaquaquecetuba, Mogi das Cruzes e adjacências. Objetiva aproximar os professores de filosofia daquela região para dar a conhecer e trazer o debate em torno daquilo que estão trabalhando em sala de aula para, por meio do intercâmbio, aprimorar o trabalho de cada um.

Associação de Professores de Filosofia do Distrito Federal e Entorno (APROFILOS): existe desde 2000, formada por professores de filosofia do ensino médio que organizam atividades visando a aprimorar sua própria prática.

Centro Brasileiro de Filosofia para Crianças (CBFC): fundado em 1985, o Centro trabalha a partir das idéias e projetos de Matthew Lipman. O Centro tem sua sede na cidade de São Paulo e possui representantes regionais em Belo Horizonte (MG), Campinas (SP), Cuiabá (MT),

Em 2004, havia previsão do IV Fórum Centro-Oeste em Tocantins, do IV Fórum Sul em São Leopoldo; do II Fórum do Sudeste no Rio de Janeiro e do I Fórum Norte em Belém. 
Curitiba (PR), Ilhéus (BA), Petrópolis (RJ) Piranguinho (MG), Recife (SP) e Ribeirão Preto (SP). Já formou mais de 13 mil professores, para o trabalho em sala de aula com o programa de "Filosofia para Crianças". O programa é desenvolvido sistematicamente em cerca de mil escolas, seja por meio de projetos do Centro, seja por meio de professores por ele formados, envolvendo, aproximadamente, 300 mil alunos. Além das cidades já mencionadas, o "Filosofia para Crianças" está presente em capitais brasileiras como Florianópolis, Porto Alegre, São Luís, Fortaleza, Vitória, Brasília, Goiânia, Manaus e Vitória, além de outras cidades do interior de outros estados como Espírito Santo, Goiás, Minas Gerais, Pará, Paraná, Rio de Janeiro, Santa Catarina, Mato Grosso do Sul, Mato Grosso e São Paulo.E-mail: cbfc@cbfc.org.br; home page: http://www.cbfc.org.br/

Centro de Estudos em Filosofia Americana (CEFA) e Portal Brasileiro de Filosofia e Filosofia da Educação (www.filosofia.pro.br): iniciativas que divulgam a filosofia e o debate em torno de seu ensino através da Internet.

Centro de Filosofia - Educação para o Pensar: entidade civil, voltada para a qualidade do ensino e da aprendizagem de crianças e jovens. Fundado em 1988, formou cerca de 2 mil professores e abrange uma rede de 37 escolas, atingindo mais de 15 mil alunos. O Centro de Filosofia desenvolve parcerias com colégios da rede particular e pública e tem representações por intermédio de 16 Núcleos de Filosofia Educação para o Pensar (NUFEP), em vários estados (Bahia, Ceará, Espírito Santo, Paraná, Rio de Janeiro, Rio Grande do Sul, Santa Catarina, São Paulo). Publica o Jornal da Filosofia Fundamental - Corujinha, a Revista Brasileira de Filosofia no Ensino Fundamental - PhiloS, e livros de filosofia com crianças e jovens em parceria com a Editora Sophos.E-mail: centro@centrofilos.org.br; home page: http://www.centro-filos.org.br/

Filosofia na Escola (UNB): área que inclui projeto de extensão permanente, cursos de graduação e pós-graduação e pesquisa de campo. Teve seu início no final do ano de 1997 e vem sendo desenvolvido na Faculdade de Educação/UnB, contando com a participação de professores de diversas escolas do DF. Tem por objetivo principal criar espaços para promover a prática filosófica com crianças, adolescentes e jovens, na educação infantil, no ensino fundamental e no ensino médio em escolas da rede pública do Distrito Federal. Conta com várias pesquisas em andamento, e uma base de dados sobre ensino de filosofia na Internet (disponível em: <http://164.41.75.30/guia/>). 
Fórum Sul dos Cursos de Filosofia: trata-se de uma associação dos cursos de filosofia da Região Sul do Brasil. O principal objetivo da associação não se restringe à luta pela filosofia no ensino médio, mas em promover discussões em torno do ensino de filosofia, inclusive no ensino médio. O Fórum foi informalmente criado em 1999 e atualmente existe uma comissão que está organizando um estatuto para oficializá-lo.

Grupo de Estudos e Pesquisas Filosofia para Crianças (GEPFC): ligado ao Programa de Pós-Graduação em Educação Escolar da UnEsP, campus Araraquara. Propõe atividades de ensino, pesquisa e extensão sobre a prática filosófica com crianças e jovens.

Grupo de Porto Alegre (Gerf): entre outros eventos que realizou ou dos quais participou estão o Encontro Estadual de Professores, em 1994, e as reuniōes anuais da SBPC de 2000 e 2001.

Grupo de Estudos sobre Ensino de Filosofia (GESEF): criado em 1995 na Universidade Metodista de Piracicaba. Realiza anualmente encontros de professores de filosofia de Piracicaba e região. Publicou em 1997 o livro Ética e cidadania: caminhos da filosofia (Campinas, SP: Papirus), voltado para o ensino da filosofia em nível médio, a partir dos estudos feitos nos encontros regionais de professores de filosofia; o livro está hoje em sua $11^{\text {a }}$ edição. Em 2000 o GESEF organizou o Congresso Brasileiro de Professores de Filosofia e em 2002 o I Simpósio sobre Ensino de Filosofia da Região Sudeste. GESEF sedia uma lista de discussão na Internet sobre ensino de filosofia, a Rede Latino-Americana de Ensino de Filosofia, surgida a partir do Congresso Internacional de Filosofia com Crianças e Jovens, organizado pelo Projeto Filosofia na Escola, da UNB, em 1999 na cidade de Brasília.E-mail: madanelo@unimep.br; home page: http://www.unimep.br/ -gesef

Instituto Superior de Estudos e Pesquisas em Filosofia e Ciências (ISEF): criado em 2002 no Distrito Federal. Instituição que fomenta os estudos e a pesquisa em filosofia e ciências, com publicações, encontros, lista de discussão e grupos de estudo, publica duas revistas: Debates do ISEF e Seleta de Filosofia e Ciências. Home page: http://www.isef.cjb.net.

Núcleo de Estudos sobre o Ensino de Filosofia (NEFI): centro de estudos, pesquisas, publicações, debates e extensão da Universidade Federal do Piauí, vinculado ao Departamento de Filosofia do Centro de Ciências Humanas e Letras, direcionado às questões gerais relativas ao ensino de filosofia em todos os seus níveis. E-mail: nefiufpi@ieg.com.br; home page: http://www.nefiufpi.hpg.ig.com.br/index.htm. 
Núcleo de Estudos sobre o Ensino de Filosofia/UfPR (NESEF): núcleo centrado na pesquisa e extensão, promove cursos de capacitação e encontros quinzenais para troca de experiências. Desenvolve um projeto de curso de Especialização sobre Ensino de Filosofia, voltado para professores das redes municipal e estadual.

Núcleo de Educação para o Pensar (NUEP): com sede em Passo Fundo, foi fundado em janeiro de 2000 e tem por principal finalidade assessorar as escolas que desejam implantar filosofia desde a educação infantil até o ensino médio. Entre as principais açóes destacam-se: cursos de capacitação de professores que pretendam conhecer e trabalhar com o projeto educação para o pensar, elaboração de subsídios teóricos e didáticos para o trabalho nas escolas e assessoria às escolas que estão desenvolvendo o projeto. Atualmente participam mais de 130 escolas da região. O núcleo possui uma articulação entre essas escolas promovendo atividades que envolvam alunos e professores. Home page: http://nuep.org.br

Projeto Pensar (CEFET-GO): voltado para a filosofia no ensino médio no CEFET-GO. E-mail: jll@cefetgo.br; home page: http://br.geocities.com/ ppensar/

PROPHIL: núcleo de pesquisa, ensino e extensão ligado ao Departamento de Filosofia da Universidade Federal de Mato Grosso, em Cuiabá. Compõe uma linha do mestrado em educação da mesma universidade, na qual foram produzidas, até o momento, várias dissertações de mestrado.

Sociedade de Estudos e Atividades Filosóficos (SEAF): com sede no Rio de Janeiro. A SEAF já teve expressão nacional e desempenhou importante papel nos debates pela volta da filosofia ao ensino médio, no final dos anos de 1970 e início dos anos de 1980. Depois do retorno opcional, naquela época, sua atuação enfraqueceu-se significativamente, mas vem sendo retomada nos últimos anos. Em 2001 e 2002 promoveu encontros estaduais de professores de filosofia. 